\title{
Measuring Logistics Service Quality
}

\author{
Theodore P. Stank \\ The University of Georgia \\ Athens, Georgia
}

Increased competition and price deregulation in many service industries have caused service providing firms to seek to differentiate themselves to remain competitive. As in manufacturing, improving the quality of the product (the service provided) is an effective way to gain this competitive advantage. The successful application of a differentiation strategy depends on the firm's ability to identify the critical service quality determinants, and then to efficiently allocate resources to develop strengths in these determinants. A proficient quality assurance system is the key to defining and measuring the service quality determinants for the firm's service area. Meaningful measures of the actual effectiveness of service quality initiatives on customer satisfaction must be developed and used [3]. Therefore, feedback from customers on the effectiveness of the strategy is critical to its long-term success.

Many manufacturing corporations, confronted by greater competitive pressures and limited resources, face difficult decisions regarding how they will meet the ever-increasing customer demand for quality. Critical to these decisions is how the firm chooses to handle its logistics function, the process by which raw materials and finished goods are moved from point of supply to end user. The central issue involves the choice between expending scarce resources developing a quality in-house logistics function or contracting this function out to external logistics service firms. While only 5 percent of the nearly $\$ 500$ billion annual domestic logistics expenditures are currently outsourced, current trends indicate that this figure is likely to double or triple in the next 10 years [13].

These external firms, known as third party logistics providers, specialize in logistics functions. The services provided by these "middle men" may include transportation, freight consolidation and packaging, warehousing, information processing services (including freight bill auditing and payment, tracking, transaction processing, MIS reporting, etc.), customs brokering, and materials management and inventory control [13]. For example, freight forwarders provide such varied services as arranging domestic and international transportation; storage, breaking and sorting materials for reshipment to end users; packing and containerization; electronic data processing of ordering, invoice, payment and tracking documentation; and customs brokerage. Increasingly, manufacturing firms are focusing resources on their core business(es) and outsourcing the logistics function to these third-party experts.

The quality of service offered by contract, or third-party, logistics firms has been identified as the most critical aspect in manufacturers' selections of logistics providers ([3], [4], [8], [9]). The level of service quality required by customers, and subsequent use of this information in the strategic planning process, are necessary components of successful competition for third party logistics firms. Measures of service quality must reflect actual customer perceptions, not operationally derived substitutes. For example, 
Federal Express Corporation, winner of the 1990 Malcolm Baldridge National Quality Award, replaced its old measure of performance quality (percent of on-time deliveries) with a 12 component index that comprehensively describes how its performance is viewed by customers. However, there is no agreed upon measure of service quality for the industry.

An instrument has been developed to aid retail firms in the definition and measurement of customers' perceptions of the determinants of service quality [10]. This instrument was designed as a generic "skeleton" that could be adapted to a great variety of service industries. Its applicability in measuring the level of service quality in several retail, professional and financial service settings has been tested with generally positive results ([2], [6], [7], [11], [12]). The instrument has also been adapted to measure the service quality perceptions of purchasers of motor carrier services in the business-to-business market [5], incorporating industry specific findings from the transportation literature [1]. It has not been applied to the many other services provided by third-party logistics firms, however.

The purpose of this paper is to propose a logistics service quality measurement tool based upon this established instrument to aid managers of third-party logistics firms, and purchasers of these services in the business-to-business marketplace, in defining and measuring perceptions of the determinants of logistics service quality. The instrument will be adapted to the logistics setting by incorporating commonly used logistics measures into the existing framework. The objectives of this adaptation are to provide third party logistics firms and the purchasers of their services with 1) a dependable delineation of critical determinants of service quality which may facilitate effective allocation of resources; and 2) a meaningful tool to measure the level of service quality on these determinants provided by the firm.

The paper first reviews the concept of logistics service quality and the attempts made recently to define and measure it. The retail service quality model and measurement instrument is then introduced and modifications are made to adapt it to the logistics service area. Finally, implications to managers and conclusions are discussed.

\section{Logistics Service Quality}

Economic and competitive pressures dictate that the success of third-party logistics firms center on the effective use of inventory assets. Pressure to more effectively utilize assets has been experienced throughout all levels of the distribution channel. Strategies designed to improve inventory turns, reduce inventory levels, and eliminate slow turn items have become important to operational managers [8]. Yet to achieve overall effectiveness, managers must focus on how these strategies impact the valueadded benefits derived by the customer. Third-party logistics firms must be cognizant of service requirements and deliver services that fulfill these requirements. These must be compatible with the firm's overall strategic objectives.

Obtaining information on customer product and service requirements in a timely and accurate manner is of utmost importance to maximize the value of the service 
provided. As a result, the subject of measurement of customer satisfaction with service quality must shift from internally generated operational features to meaningful measures which actually tap the customers' perception of the service quality provided. This will allow executives to be proactive in the management of an important strategic weapon of competitive advantage.

The particular dimensions used to define and measure customer service are dependent upon the industry in which the firm competes and the functional area of the respondent. Little standardization of the dimensions of customer service exists within logistics firms. This has created problems in designing an instrument to measure customer satisfaction levels. As a result, many third-party logistics firms rely on operational measures such as delivery and/or inventory reliability, speed of order fulfillment, and/or transit time to generate an internal measurement of service quality. More meaningful measures of service quality must be based upon the customers' perception of the value of service received. These measures must reflect service dimensions identified by businesses as critical to the performance of logistics functions.

\section{Measurements of Customer Service in Logistics}

Research on customer service in logistics has indicated that certain characteristics or dimensions of service are particularly important in the logistics setting, although no standardized measurement tool has been proposed. The following dimensions of customer service have been identified in past research as areas critical to the satisfaction of customers of third-party logistics firms [8]:

\section{Pre-transaction Elements}

1. Written statement of policy

2. Customer receipt of policy statement

3. Organizational structure

4. System flexibility

5. Management services

\section{Transaction Elements}

1. Stock-out levels

2. Order information

3. Elements of order cycle

4. Expedition of shipments

5. Transshipment

6. System accuracy

7. Order convenience

8. Product substitution 


\section{Post-transaction Elements}

1. Installation, warranty, alterations, repair parts

2. Product tracing

3. Customer claims, complaints, returns

4. Temporary replacement of product

The strong emphasis on service functions indicated by these dimensions reflects the trend toward creating customer satisfaction through service quality. Subsequent studies have continued this trend. A study on the critical characteristics of leading logistics firms included the following features used by customers to evaluate logistics providers ([4], pp. 205-206):

1. Customer support

2. Easy to work with

3. Good communication

4. Early notification

5. Flexibility

6. Willing to customize service

These features summarize the critical dimensions of customer service identified in the earlier study. They also resemble the ten determinants used in developing the retail service quality measurement instrument. Table 1 provides the ten key service determinants and their definitions from the original retail service quality study [11], as well as common logistics-related measures of these determinants. An instrument designed to measure customers' perceptions of these determinants would provide managers of third-party logistics firms with a meaningful assessment of the competitive advantage created by the level of service quality provided.

\section{Table 1: Determinants of Service Quality and Corresponding} Common Logistics Measures

Reliability: consistency of performance and dependability

- avoidance of work stoppage/stock-outs

- meets promised deadlines

- on-time pick-up/delivery

Responsiveness: willingness or readiness of employees to provide timely service

- delivery speed/transit-time

- delivers services when requested

- meeting client deadlines

Competence: possession of the required skills and knowledge to perform the service

- knowledge/expertise

- quality of personnel 
Table 1: Determinants of Service Quality and Corresponding Common Logistics Measures (Continued)

Access: approachability, ease of contact, and availability of services

- availability of service equipment

- convenient schedule

- frequency of service

- geographic area served

- pick-up and delivery service

Courtesy: politeness, respect, consideration, and friendliness of contact personnel

- co-operation

- rapport

- ready/willing to help

- responsiveness to request

Communication: keeping customers informed in language they can understand; listening - ability to follow instructions

- information provided to user

- listening to demands

Credibility: trustworthiness, believability, honesty, acts in the customer's best interests

- experience

- financial stability

- past performance

- reputation/image

- trustworthy

Security: freedom from danger, risk, or doubt

- claims processing record

- loss and damage record

- tracing capabilities

Understanding: making the effort to understand the customers's needs

- flexibility

- co-operative planning

Tangibles: physical evidence of the service

- equipment capabilities

- physical facilities/special services/equipment available

\section{A Service Quality Model}

Unlike tangible goods quality, which can be defined and measured by objective attributes, defining and measuring service quality is a difficult task which must take into account the unique characteristics of services. Four characteristics are generally considered to distinguish services from goods: intangibility, inseparability of production and consumption, heterogeneity, and perishability [10]. Intangibility refers to the 
fact that services do not possess objective attributes which can be measured, such as durability or number of defects. Inseparability of production and consumption involves the simultaneous production and consumption of services provided to consumers. Heterogeneity concerns the potential for high variability in the level of service provided, depending upon the actual employee of the service firm providing the service at the time of consumption. Perishability means that service customers cannot consume the service at a later time, but rather must consume the service (i.e., be served) at the time the service is rendered.

Each characteristic unique to services leads to particular problems for service marketers. A definition of service quality and its determining factors (as identified by retail service providers and consumers in a national study) have been developed [10]. The definition attempts to capture the unique problems faced by managers of service firms and the strategies used to overcome them. This approach identifies four "gaps" occurring in organizations that can cause quality problems. These gaps are defined as follows:

1. Marketing Information Gap: inadequate or inaccurate understanding of customer's service expectations.

2. Standards Gap: failure to develop performance specifications reflecting customer's expectations.

3. Service Performance Gap: discrepancy between performance specifications and service actually delivered.

4. Communication Gap: discrepancy between descriptions of the service to customers and service actually delivered.

These organizational gaps create a gap between customers' expectations of the quality of service prior to consumption and their perceptions of it following consumption. This final gap is the ultimate gauge of the customers' evaluation of the level of service quality provided.

The critical dimensions or determinants used by customers in assessing service quality have been identified in a study conducted to measure retail service quality [11]. With minor modifications (e.g. changing industry specific wording, deleting inapplicable items, or adding items pertinent to the industry) this instrument may be adapted to other industries or service settings including business-to-business logistics. Table 1 identifies the critical determinants used in the retail service quality model along with common measures of these determinants used in the logistics setting.

\section{Modification of the Measurement Instrument}

The retail service quality measurement instrument was designed to allow adaptation by a great variety of service industries. It has been successfully adapted for many other retail, professional, and financial service settings ([2], [6], [7], [11], [12]). Some recommendations to improve the instrument have resulted from these efforts [6]. One 
such recommendation regarded collecting importance weights assigned by the customer to each quality determinant. Importance weights are relevant to the concept of service quality used here, since overall service quality is equivalent to the summation of the individual service determinant expectation-perception differences, multiplied by the importance weight assigned by respondents to that determinant. Therefore, the importance weights are just as critical in determining the contribution of the individual determinants to overall quality as the differences in perceptions and expectations are. Importance weights for each service feature could be collected at the same time as the service quality difference data. Alternatively, importance weights could be collected separately. Averaged weights could then be used with subsequent measurements of expectation-perception differences.

Another recommendation regarded the administration of the instrument. The original method called for collecting customer expectation data prior to receiving the service and collecting customer perception data after consuming the service. This method created practical difficulties because service providers were often unwilling to allow collection of expectation data before provision of the service. Therefore, it was recommended that the items ask about the customer's expectation-perception differences, rather than ask separate questions about each and subtracting one score from the other.

Modifications to the retail service quality instrument regarding industry specific wording, deletions of inapplicable items, and additions of pertinent items have been made based upon the critical logistics service determinants identified earlier and the common logistics-related measures presented in Table 1. The Appendix contains the measurement instrument, as adapted for the logistics service setting.

\section{Implications and Conclusions}

The ability to meaningfully measure the level of service quality as perceived by a firms' customers is critical to the effectiveness of customer service differentiation strategies. Quality assurance has become standard for goods-producing firms. However, the intrinsic nature of services has made it difficult for service firms to assess the level of quality provided to customers. While other customer-oriented programs have been adopted by service firms, the difficulty of measuring service quality from the customers standpoint has limited their success. As a result, the ability to utilize the value of a customer service orientation to create competitive advantage has been limited.

Adapting an instrument which measures the customers' perception of the quality of service received from third-party logistics firms will enable managers of those firms to anchor service quality assurance programs on meaningful quality assessments. The purpose of this paper is to propose an instrument which will enable third-party logistics firms to determine and measure the critical determinants of logistics service quality. With the instrument proposed here as a tool, managers of logistics firms will be able to ascertain the actual effectiveness of service initiatives as opposed to depending upon internally generated operational performance measures. 
Additionally, managers of these firms will be able to customize service programs based upon the importance of the determinants to customers. This will make it possible to highlight those service areas considered critical to each customer by allocating resources to the areas providing the greatest impact on quality. The result will be more efficient and effective service quality programs, creating greater value for customers.

The instrument may also be used by firms purchasing services from third-party logistics providers as an objective internal measurement of satisfaction with the level of quality received. This could prove particularly useful in firms that receive logistics services across functional areas. An aggregate service quality score compiled by managers of the different functional areas using the services of a particular logistics firm would be useful. The measure could also be used by firms that purchase the same logistics services from multiple third-party providers, using the results as an objective comparison between firms.

This tool should find ready acceptance among providers and purchasers of thirdparty logistics services. With escalating costs of logistics activities, managers need meaningful measures of the output of logistics service. The success of the instrument in the related service areas of retail, professional and financial services should provide managers with the assurance they need to utilize it. Previous testing of the instrument in these related service areas indicated that the scale was a valid and reliable tool for measuring service quality. The focus of future research must be to empirically test this adaptation of the instrument to ensure its validity and reliability in the logistics service setting.

To summarize, service providers, like manufacturers, must have quality assurance programs to monitor the level of service quality. The instrument presented here proposes a meaningful measurement of customers' perceptions of logistics service quality by incorporating commonly used logistics service measures into an established scale of service quality. This will make it possible for purchasers and providers of logistics services to manage resources more efficiently and effectively.

\section{References}

1. Abshire, R.D. and Premeaux, S.R. "Motor Carrier Selection Criteria: Perceptual Differences Between Shippers and Carriers." Transportation Journal, Vol. 31 (1991), pp. 31-35.

2. Babakus, E. and Boller, G.W. "An Empirical Assessment of the SERVQUAL Scale." Journal of Business Research, Vol. 24 (1992), pp. 253-268.

3. Bowersox, D.J., Daugherty, P.J., Droge, C.L., Germain, R.N., and Rogers, D.S. Logistical Excellence: Its Not Business as Usual. Burlington, MA: Digital Press (1992).

4. Bowersox, D.J., Daugherty, P.J., Droge, C.L., Rogers, D.S., and Wardlow, D.L. Leading Edge Logistics: Competitive Positioning for the 1990s. Oak Brook, IL: The Council of Logistics Management (1989). 
5. Brensinger, R.P. and Lambert, D.M. "Can the SERVQUAL Scale be Generalized to Business-to-Business Services?" in Knowledge Development in Marketing, 1990 AMA's Summer Educators' Conference Proceedings (1990), p. 289 (abstract).

6. Carman, J.M. "Consumer Perceptions of Service Quality: An Assessment of the SERVOUAL Dimensions.” Journal of Retailing, Vol. 66 (1990), pp. 33-55.

7. Finn, D.W. and Lamb, C.W. "An Evaluation of the SERVQUAL Scales in a Retailing Setting." Advances in Consumer Research, Vol. 18 (1991), p. 18.

8. LaLonde, B.J. and Zinszer, P.H. Customer Service: Meaning and Measurement. Oak Brook, IL: The Council of Logistics Management (1976).

9. LaLonde, B.J., Cooper, M.C., and Noordewier, T.G. Customer Service: A Management Perspective. Oak Brook, IL: The Council of Logistics Management (1988).

10. Parasuraman, A., Zeithaml, V.A., and Berry, L.. “A Conceptual Model of Service Quality and Its Implications for Future Research.” Journal of Marketing, Vol. 49 (1985), pp. 4150 .

11. Parasuraman, A., Zeithaml, V.A., and Berry, L.L. "Consumer Perceptions of Service Quality: An Assessment of the SERVQUAL Dimensions." Journal of Retailing, Vol. 64 (1988), pp. 33-55.

12. Parasuraman, A., Zeithaml, V.A., and Berry, L.L. (1991), "Refinement and Reassessment of the SERVQUAL Scale.” Journal of Retailing, Vol. 67 (1991), pp. 420-450.

13. Sheffi, Y. "Third Party Logistics: Present and Future Prospects." Journal of Business Logistics, Vol. 11 (1990), pp. 27-39. 


\section{Appendix: Adaptation Of The Measurement Instrument}

Directions: This survey deals with how you feel XYZ company met your expectations of the level of service which should be provided by logistics firms. A list of possible service features is given below. For each service feature described, please show the extent to which you think the service provided by XYZ met your expectations of what that service should be. Do this by circling one of the seven numbers next to each statement. If you strongly agree that the level of the service feature provided by $\mathrm{XYZ}$ met your expectations exactly, circle number 1 . If you strongly disagree that the level of the service feature provided by XYZ met your expectations, circle number 7. If your feelings are not strong, circle one of the numbers in the middle that best shows how closely the level of the service feature actually provided by XYZ came to your expectations. For example, circling number 3 would indicate that the service provided more closely matched your expectations than circling number 4 would indicate, but not as closely as circling number 2 would indicate.

I. Please respond to the following statements regarding XYZ. The XYZ firm:

\section{Strongly \\ Agree}

Strongly

Disagree

1. provides up-to-date equipment.

2. maintains modern, efficient facilities.

$\begin{array}{lllllll}1 & 2 & 3 & 4 & 5 & 6 & 7 \\ 1 & 2 & 3 & 4 & 5 & 6 & 7 \\ 1 & 2 & 3 & 4 & 5 & 6 & 7 \\ 1 & 2 & 3 & 4 & 5 & 6 & 7\end{array}$

3. meets promised deadlines.

4. deals with customer problems in a sympathetic $1 \quad 2 \quad \begin{array}{llllll}1 & 2 & 4 & 5 & 6 & 7\end{array}$ and reassuring way.

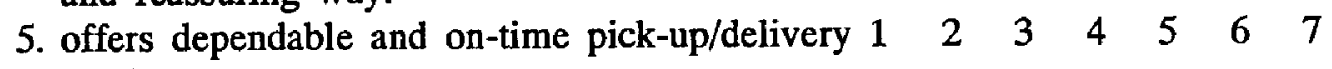
service.

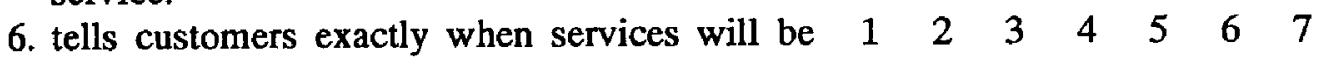
performed.

$\begin{array}{llllllll}\text { 7. has fast and accurate information and records } & 1 & 2 & 3 & 4 & 5 & 6 & 7\end{array}$ tracing capabilities.

8. delivers prompt service.

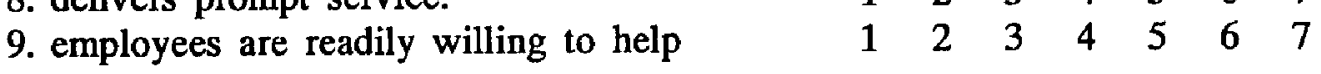
customers.

10. employees are not too busy to respond to $\quad \begin{array}{llllllll}1 & 2 & 3 & 4 & 5 & 6 & 7\end{array}$ requests.

11. employees are trustworthy.

12. cooperates with customer to help him/her do $\begin{array}{llllllll}1 & 2 & 3 & 4 & 5 & 6 & 7\end{array}$ the job well.

13. is flexible, provides service tailored to customer needs.

14. knows the needs of its customers.

$\begin{array}{lllllll}1 & 2 & 3 & 4 & 5 & 6 & 7\end{array}$

$\begin{array}{lllllll}1 & 2 & 3 & 4 & 5 & 6 & 7\end{array}$ 
15. knows its own business well.

16. employees are highly qualified for their jobs. $\begin{array}{llllllll}1 & 2 & 3 & 4 & 5 & 6 & 7\end{array}$

17. provides operating hours convenient to their $\begin{array}{llllllll}1 & 2 & 3 & 4 & 5 & 6 & 7\end{array}$ customers.

18. provides services which allow customers to $\begin{array}{llllllll}1 & 2 & 3 & 4 & 5 & 6 & 7\end{array}$ avoid work stoppages or stock-outs.

19. provides service to the geographic area of the $\begin{array}{llllllll}1 & 2 & 3 & 4 & 5 & 6 & 7\end{array}$ customer's market.

20. provides frequent service.

21. provides door-to-door pick-up and delivery $\quad \begin{array}{llllllll}1 & 2 & 3 & 4 & 5 & 6 & 7\end{array}$ service.

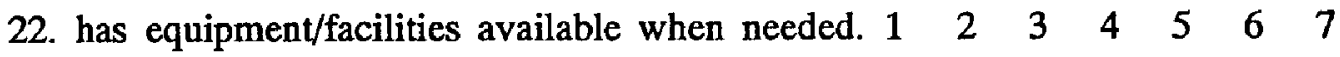

23. listens to customer demands and needs. $\quad \begin{array}{llllllll}1 & 2 & 3 & 4 & 5 & 6 & 7\end{array}$

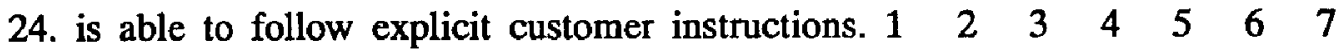

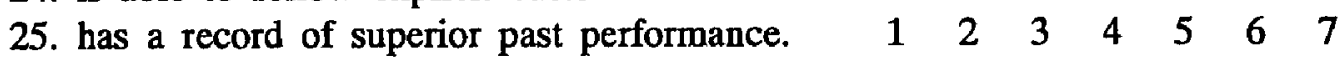

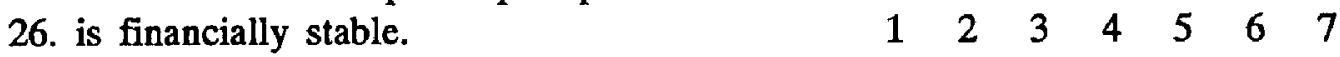

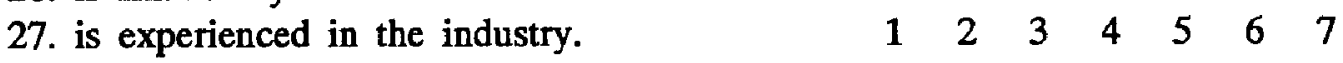

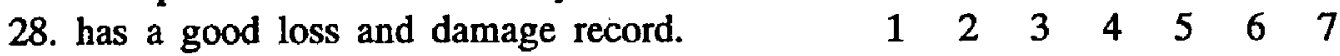

29. accepts and processes claims rapidly. $\quad \begin{array}{llllllll} & 1 & 2 & 3 & 4 & 5 & 6 & 7\end{array}$

30. possesses the equipment necessary to meet $\quad \begin{array}{llllllll}1 & 2 & 3 & 4 & 5 & 6 & 7\end{array}$ customer's special needs.

II. For the following statements, please indicate how important you feel each is to the overall quality of logistics service provided by XYZ. The XYZ firm:

\section{Extremely Not Im- \\ Important portant}

1. provides up-to-date equipment.

2. maintains modern, efficient facilities.

3. meets promised deadlines.

4. deals with customer problems in a sympathetic and $\quad \begin{array}{lllll}1 & 2 & 3 & 4 & 5\end{array}$ reassuring way.

5. offers dependable and on-time pick-up/delivery service. $\begin{array}{llllll}1 & 2 & 3 & 4 & 5\end{array}$

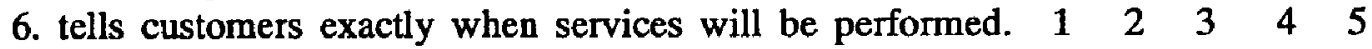

$\begin{array}{llllll}\text { 7. has fast and accurate information and records tracing } & 1 & 2 & 3 & 4 & 5\end{array}$ capabilities.

8. delivers prompt service.

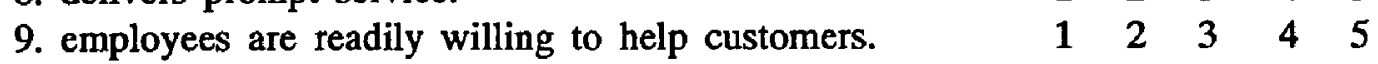


10. employees are not too busy to respond to requests.

$\begin{array}{lllll}1 & 2 & 3 & 4 & 5\end{array}$

11. employees are trustworthy.

12. cooperates with customer to help him/her do the job well. $\begin{array}{llllll}1 & 2 & 3 & 4 & 5\end{array}$

13. is flexible, provides service tailored to customer needs. $\begin{array}{llllll}1 & 2 & 3 & 4 & 5\end{array}$

14. knows the needs of its customers.

$\begin{array}{lllll}1 & 2 & 3 & 4 & 5\end{array}$

15. knows its own business well.

$\begin{array}{lllll}1 & 2 & 3 & 4 & 5\end{array}$

16. employees are highly qualified for their jobs.

$\begin{array}{lllll}1 & 2 & 3 & 4 & 5\end{array}$

17. provides operating hours convenient to their customers. $\begin{array}{llllll}1 & 2 & 3 & 4 & 5\end{array}$

18. provides services which allow customers to avoid work $\begin{array}{llllll}1 & 2 & 3 & 4 & 5\end{array}$ stoppages or stock-outs.

19. provides service to the geographic area of the customer's $\begin{array}{lllll}1 & 2 & 3 & 4 & 5\end{array}$ market.

20. provides frequent service.

$\begin{array}{lllll}1 & 2 & 3 & 4 & 5\end{array}$

21. provides door-to-door pick-up and delivery service. $\quad \begin{array}{llllll}1 & 2 & 3 & 4 & 5\end{array}$

22. has equipment/facilities available when needed.

$\begin{array}{lllll}1 & 2 & 3 & 4 & 5\end{array}$

23. listens to customer demands and needs.

24. is able to follow explicit customer instructions.

25 . has a record of superior past performance.

26 . is financially stable.

27. is experienced in the industry.

28. has a good loss and damage record.

29. accepts and processes claims rapidly.

30. possesses the equipment necessary to meet customer's $\begin{array}{llllll}1 & 2 & 3 & 4 & 5\end{array}$ special needs. 